\title{
Research into the Present Situation and Developing Strategies of Agricultural Insurance in Fujian Province
}

\author{
Shouli Zhang ${ }^{1, a^{*}}$ and Ruiqiang Yang ${ }^{1, b}$ \\ ${ }^{1}$ School of Economics and Management of Jilin Agriculture University \\ a287639262@qq.com, b1308091460@qq.com
}

Keywords: Agricultural Insurance; Agricultural development; Countermeasure; Fujian province

\begin{abstract}
Agriculture is the foundation for national economy, the sustained and healthy development of agriculture is of great significance to the stability of the entire national economy. Natural disasters and market risk are great threats to the agricultural development, therefore, agricultural insurance is in urgent need to transfer the potential risks. The analysis on the development of agricultural insurance in Fujian Province presents a few problems: the lack of government support, due to insufficient tax policies on agricultural insurance; the lack of attention from insurance companies, and their unstandardized management behavior. In view of the problems above, the paper gives suggestions on countermeasures.
\end{abstract}

\section{Introduction}

Located on the southeast coast of China, Fujian province has a complicated landscape, a changing climate, a variety of crop diseases and pests, frequent occurrences of natural disasters, such as typhoon, rainstorm, and drought. Farmers' decentralized operation on a small-scale makes it more difficult to control the risks, accounting for the low income and agricultural production. By means of agricultural insurance, insurance companies can provide financial security when economical loss happens due to natural disasters or accidents for farmers working on farming and stockbreeding [1]. However, the agricultural insurance has not spread as hoped in Fujian Province since its launch. Therefore, it is of practical significance to study the effective way to promote of the agricultural insurance in Fujian province.

\section{The Present Development of Agricultural Insurance in Fujian Province}

According to statistics, the agricultural insurance accounts for $2.62 \%$ of the country's property insurance at the beginning of 2015 , taking up $0.57 \%$ in the gross income of premium, while the agricultural insurance in Fujian Province accounts for $1.81 \%$ of the province's property insurance, taking up $0.03 \%$ in the gross income of premium. Compared with the average of the nation, the agricultural insurance constitutes a lower portion not only in the property insurance, but also in the total premium income in Fujian Province. Judging from the insurance distribution in Fujian Province, the share of agricultural insurance in Fujian province is quite inadequate and negligible, whose development is lagging far behind.

On the other hand, the premium on agricultural insurance in Fujian Province has been increasing every year, from a total of 12,417 yuan in 2009 to 44,400 yuan in 2015 , experiencing a entire growth of $72 \%$; the insurance indemnity has also risen by $72.2 \%$, from a total of 7,657 yuan in 2009 to 27,500 yuan in 2015 . The expansion in insurance indemnity indicates that farmers are raising their insured amount, and the range of the promotion of agricultural insurance is also expanding.

\section{Main Problems in the Development of Agricultural Insurance in Fujian Province}

The Lack of Aovernment Support, without Preferential Tax Policies on Agricultural Insurance. National financial support for agricultural insurance in Fujian has not grown with time. In terms of government, national financial funds are put into a wide range of use, and there is no financial resources left to keep the agricultural insurance business, as a consequence, government is 
not willing to inject quantities of funds to the development of agricultural production. In addition, the mechanism for the diversification of risk under state financial support has not been set up completely, and the mechanism to disperse the losses under catastrophes is not yet strengthened. Except for the current premium allowance given to farmers, there has not been a set of regulations issued encouraging insurance companies to promote agricultural insurance business supporting the farmers [2]. Therefore, it is necessary to establish a set of finance and taxation policies efficient and effective with regard to agricultural insurance. Practice has proved that if there is no support from state financial subsidies, agricultural insurance business will not have a sustained and stable development, with its high risk, high costs and high payment rate.

Insurance Companies do not pay Sufficient Attention, and Management is Non-Standardized. In the agricultural insurance market of Fujian Province, the insurance liability of most products is unable to meet farmers' actual needs to resist risk. Therefore, there is a lack of insurance awareness, resulting in the slow development of policy-oriented agricultural insurance.

In addition, insurance companies are weak in the techniques on risk monitoring, evaluation, and collection in agricultural production, as well as its technique on the measurement and actuarial calculation of the losses caused by agricultural disasters [3].

Firstly, insurance companies sets up fewer outlets in the village, and there is an absence of management personnel researching into the development of agricultural insurance market, therefore, agricultural insurance services are still remaining on a primary stage. Second, the operation and management in agricultural insurance are not yet standardized. In the management of the agricultural insurance, there are some insurance companies colliding with government departments making false underwriting and compensation promises, to cash in subsidies illegally. In policy-oriented agricultural insurance business, some government departments, enterprises and institutions extract or ask for fees from the insurance companies through their administrative power and resource. In terms of risk control, due to the unpredictability of disasters, inadequate rural statistical system, the lack of basic information and many other factors, it is still hard to enforce the scientific management of agricultural insurance [4].

The Farmers' Cultural Quality is Low, and the Awareness of Agricultural Insurance is Weak. Under the influence of the traditional agricultural operation mode, modern agricultural insurance has not found a popular acceptance in Fujian province. Farmers have little understanding of the losses caused by the disasters, and they have doubts whether insurance companies can settle timely claims impartially, whether they settle claims at all and whether they can get direct distribution of agriculture subsidies. These problems have seriously discouraged farmers from buying agricultural insurance [5]. In addition, the current population structure in rural Fujian province also restricts farmers' demand for agricultural insurance. At present, illiterate and semi illiterate population in rural Fujian province still accounts for $3.2 \%$ of the total population, and occupy the remote villages and mountainous areas, where schooling is poor; meanwhile, there are more women than men and more elders and children than young workforce in rural population [6]. This unbalanced population structure is impeding the increase of insurance rate and the process of agricultural modernization.

\section{Strategies for the Development of Agricultural Insurance in Fujian Province}

Government should Determine the Development Strategy of Agricultural Insurance, and Introduce Supporting Policies. Government's general idea and policy choices play decisive roles on the development of agricultural insurance business. First of all, government should commit part of the funds from their revenues each year to develop agriculture insurance business in policy-oriented agricultural insurance companies [7]. Secondly, it is suggested that government should streamline redundant personnel, straighten out financial distribution structure, put more efforts on the management and supervision of administrative expenditure, which means to reduce and eventually eliminate the expenses on projects for vanity and government's reputation, turning the saved funds into supplementation for agricultural insurance fees [8]. Thirdly, government should make alterations to traditional means of disaster-relief and agriculture supporting, ensure that funds 
be used in the promotion of policy-oriented agricultural insurance, and enhance farmers' ability on risk resistence through the improvement of the overall policy support system on agricultural insurance. Last but not the least, the fund saved and agricultural catastrophe risk fund set up by the provincial government must be applied to the development of policy-oriented agricultural insurance.

Insurance Companies Should Strengthen Internal Management and Supervision, and Expand the Coverage of Agricultural Insurance. The insurance company underwriting agricultural insurance is the integral force in the development of agricultural insurance. Therefore, insurance companies should strengthen internal management and supervision. Government is expected to introduce feasible policies to promote the companies' reinforcement on internal management, training and appraisals, supervise the introduction of a set of regulations with regard to underwriting, settlement and service, upholding the basic requirements given by the China Insurance Regulatory Commission [9]. Besides, insurance companies should expand the coverage of agricultural insurance, and take initiative to design new types of insurances according to actualities in agricultural production, to provide more powerful support to agricultural production and management to the maximum extent, instead of restricting the insurances in planting and breeding only. Furthermore, the insurance companies should have active discussion in relation to the strategies of agricultural insurance business. Since the insurance industry is closely concerned with financial institutions and relevant government departments, it is necessary for the insurance companies to seek for assistance from and collaboration with relevant financial institutions and government departments, in order to draw insurance guarantee for farmers if disasters happen [10].

To Strengthen the Leadership and Public Opinion, Improve the Cultural Quality of Farmers and Agricultural Insurance Awareness. Farmers are in lack of sufficient understanding of insurance and insurance awareness, which makes it necessary to disseminate insurance knowledge vigorously and popularize agricultural insurance. Firstly, government should work for the promotion of agricultural insurance. Under the collaborative structure in which government acts as the leader, insurance companies as operators, and farmers as the main body, government should take it as a mater of urgency to increase publicity on policy-oriented agricultural insurance, which can mobilize the forces of cadres in extensive rural areas, making sure agricultural insurance is widely and effective publicized. Second, agricultural insurance should be driven by adequate settlement of claims. It will stimulate farmers' enthusiasm for agricultural insurance, if they can get compensation for their rice, corn, potato and other crops affected by typhoons, rainstorms and other natural disasters after the invasion, which will increase their ability to resist risk and promote policy-oriented agricultural insurance [11]. Third, government should speed up advancing rural informatization construction. Government should accelerate its informatization construction in rural areas, and optimize the means of information dissemination, taking full advantage of a variety of media platforms such as mobile phone, Internet, radio and television to disseminate information, providing a platform for agricultural insurance and agricultural insurance theories for farmers, in order to create a favorable cultural conditions for farmers to improve their cultural qualities.

\section{Conclusion}

It is crucial to the overall economy of Fujian Province to develop the agricultural insurance effectively. It is a long-term commitment to bring into full play the agricultural insurance's role as the tool for stabilizing social economic order and alleviating poverty, and maintaining a sustained and healthy development. In summary, the provincial government must increase their investment on policy-oriented agricultural insurance, make adjustments on financial distribution, and streamline redundant personnel. The provincial government should focus on policy subsidy by means of laws and regulations and provide a platform for agricultural insurance to guide its development [12]. Furthermore, insurance companies should expand the coverage of agricultural insurance, and develop new kinds of insurance to meet the needs of farmers. Finally, farmers should improve their cultural qualities and awareness for agricultural insurance, receiving the recognition for the importance of agricultural insurance. 


\section{Reference}

[1] Q.Q. Sun: the construction of China legal system of agricultural insurance in Hunan province (MS. Henan Normal University, China 2011),p.3 4.(In Chinese).

[2] Y.J. Chen, R.H. Lei: Factors of $\mathrm{J}$ in Fujian Province, the development of agricultural insurance policy. Modern agricultural science and technology, (2011)No.24,p.384 385.(In Chinese).

[3] Z.T. Chen: Fujian Province Agricultural Insurance Development Research(MS.Fujian Agriculture And Forestry University, China 2011), p.8 9.(In Chinese).

[4] H. Zhang : a study on the balanced relationship model of agricultural insurance interest subjects: a case study of Fujian province(MS. Northwest Agriculture and Forestry University, China 2013),p.18 20.(In Chinese).

[5] X.J. Yang, B.C. Liu and Y.Liu: Agricultural insurance Chinese nearly 10 years of practice and research progress of $\mathrm{J}$. The herald Chinese agricultural science and technology, Vol.2 (2012) No.14 ,p. $23 \sim 24$. (In Chinese).

[6] C.Wang: the coastal area Chinese D study of agricultural insurance policies (Ph.D. Ocean University of China, China 2011),p.9 10.(In Chinese).

[7] H. Fu: Research on the development of policy oriented agricultural insurance in Fujian, South China, (2011) No.15,p. $66 \sim 67$.(In Chinese).

[8] Y. Ren: Fujian agricultural insurance operation instability on J. Journal of Zaozhuang University, Vol.30 (2013) No.10,p. $109 \sim 110$.(In Chinese).

[9] Z.X. Wang:The prince of fast, small scale farmers' agricultural insurance in Fujian province in Zhangzhou city as an example .(Fujian Agriculture And Forestry University, China 2012),p.6 8.(In Chinese).

[10]Z.Y. Lin: Some thoughts on promoting policy oriented agricultural insurance pilot in Fujian, Fujian finance, (2006) No.1, p.41 42. (In Chinese).

[11]H.M. Zheng, W.P. Liu: Current situation and Strategiesof agricultural insurance for agricultural enterprises in Fujian, Journal of Fuzhou University, (2013) No.3, p.54 55. (In Chinese).

[12]G.Z. Tuo: Let the scientific research to better serve the construction of the agricultural insurance system, Insurance research, (2013) No.9,p. $16 \sim 17$.(In Chinese). 